\title{
Assessing Role of Major Drivers in Recent Decline of Monarch Butterfly Population in North America
}

\author{
Joseph Belsky and Neelendra K. Joshi* \\ Department of Entomology, University of Arkansas, Fayetteville, AR, United States
}

Monarch (Danaus plexippus L.) is a long distance migratory species of butterfly in North America that has experienced population declines in recent years. Several interacting factors have been postulated to contribute to this decline. For example, reduced overwintering habitat in Mexico as a result of logging leading to deforestation and reduced breeding habitats in the United States. Decreased spring breeding populations and inclement weather patterns have also been proposed. Herbicides are commonly used in many agricultural production systems planted with genetically modified (GM) cultivars that are resistant to these chemicals. However, the non-target effects of these commonly used herbicides to the monarch host-plant, milkweed (Asclepias spp. L.),

OPEN ACCESS

Edited by:

Enrique Martínez-Meyer, Universidad Nacional Autónoma de

México, Mexico

Reviewed by:

John Pleasants,

lowa State University, United States

Francesco Carotenuto,

Università degli Studi di Napoli

Federico II, Italy

*Correspondence:

Neelendra K. Joshi

nkjoshi@uark.edu

Specialty section:

This article was submitted to

Conservation,

a section of the journal

Frontiers in Environmental Science

Received: 20 December 2017

Accepted: 20 July 2018

Published: 24 August 2018

Citation:

Belsky J and Joshi NK (2018) Assessing Role of Major Drivers in

Recent Decline of Monarch Butterfly

Population in North America.

Front. Environ. Sci. 6:86.

doi: 10.3389/fenvs.2018.00086 which commonly grows within GM planted agricultural fields has also been hypothesized to explain reduced breeding habitats in the midwestern United States. Currently, significant uncertainty regarding the dynamics of these multiple hypotheses and how their interaction may impact the eastern monarch butterfly population remains. Meanwhile, several efforts to help monarchs have been launched; for example, milkweed plantings and campaigns to minimize deforestation in overwintering habitats. In this context, this mini-review highlights different population decline hypotheses and conservation initiatives and discusses knowledge gaps in awareness and research efforts to mitigate the eastern monarch butterfly population decline.

Keywords: monarch, pesticides, GM crops, herbicides, milkweed, landscape

\section{INTRODUCTION}

Monarch [Danaus plexippus (L.) (Nymphalidae: Danainae)], a long distance migratory species of butterfly in North America, has experienced a significant population decline in recent years. The eastern population migrates annually from its overwintering habitats in central Mexico to its breeding and feeding ranges (summer habitats) in the eastern and midwestern United States and southern regions of Canada. Several interacting factors have been reported to be associated with the decline of the Eastern population of monarch butterflies in this region (Figure 1). A reduction in quality of overwintering habitat in Mexico, a sharp decrease of breeding habitat in the United States, periodic extreme weather conditions that reduce spring breeding populations (Brower et al., 2012), and modern agronomic practices including various pest management tactics have all been implicated. The Western monarch butterfly population migrates annually from its overwintering habitats along the California coast to its breeding and feeding ranges (summer habitats) in the western United States west of the Rocky Mountains. Western monarch butterflies are also in decline, however possible reasons have not been well-studied. Larvae of monarch butterfly 
are specialist herbivores of various species of milkweeds (Asclepias spp. L., Asclepiadaceae). Monarchs breed and reproduce as they subsequently migrate northward from Mexico into the United States and southern Canada during the spring and summer months. Each year, 3-5 successive generations are produced, with the final generation making the return annual migration to central Mexico during the autumn months (Brower, 1996). A decrease in milkweed density in maize and soybean fields in the midwestern United States resulting from increased herbicide use has been proposed as a contributing factor to monarch population declines (Pleasants and Oberhauser, 2013). In particular, planting of glyphosate-tolerant crop varieties has led to increased spraying of glyphosate, which is hypothesized to have subsequently reduced milkweed abundance and thereby diminished monarch breeding habitats in this region (Pleasants and Oberhauser, 2013). Monarch parasites such as protozoan spores and their geographic distribution throughout different monarch populations have also been implicated in affecting monarchs. In the recent past, natural factors, such as seasonal changes in climate and extreme weather conditions (throughout the monarch's range) have additionally been suggested to be contributing to the monarch population decline (Vidal and Rendón-Salinas, 2014). In this short review, we discuss these multiple factors implicated in recent monarch butterfly declines
(Figure 1), and present updates on monarch conservation efforts in North America.

\section{MODERN PEST MANAGEMENT PRACTICES AND MONARCH DECLINE}

The increased usage of pesticides in conventional agriculture has been implicated as a causative factor of monarch population declines (Pecenka and Lundgren, 2015). Neonicotinoid insecticides have been widely incorporated into commercial agriculture recently compared to the decline of eastern monarchs, therefore they may not be a primary driver of monarch declines, which have occurred since the 1990's (Brower et al., 2012). Moreover, by the time neonicotinoids were widely used (Elbert et al., 2008), milkweed plants were largely absent from agricultural fields (Pleasants and Oberhauser, 2013), thereby decreasing the potential for in-field neonicotinoid exposure of monarch larvae. However, scientists are currently investigating whether neonicotinoid drift from agricultural fields to adjacent milkweed plants is a problem. For instance, it has been determined that monarch larvae exposed to clothianidin (a neonicotinoid insecticide) by feeding on milkweed grown in clothianidin-sprayed maize fields can be negatively impacted, and sub-lethal effects on larval size are observed when exposed

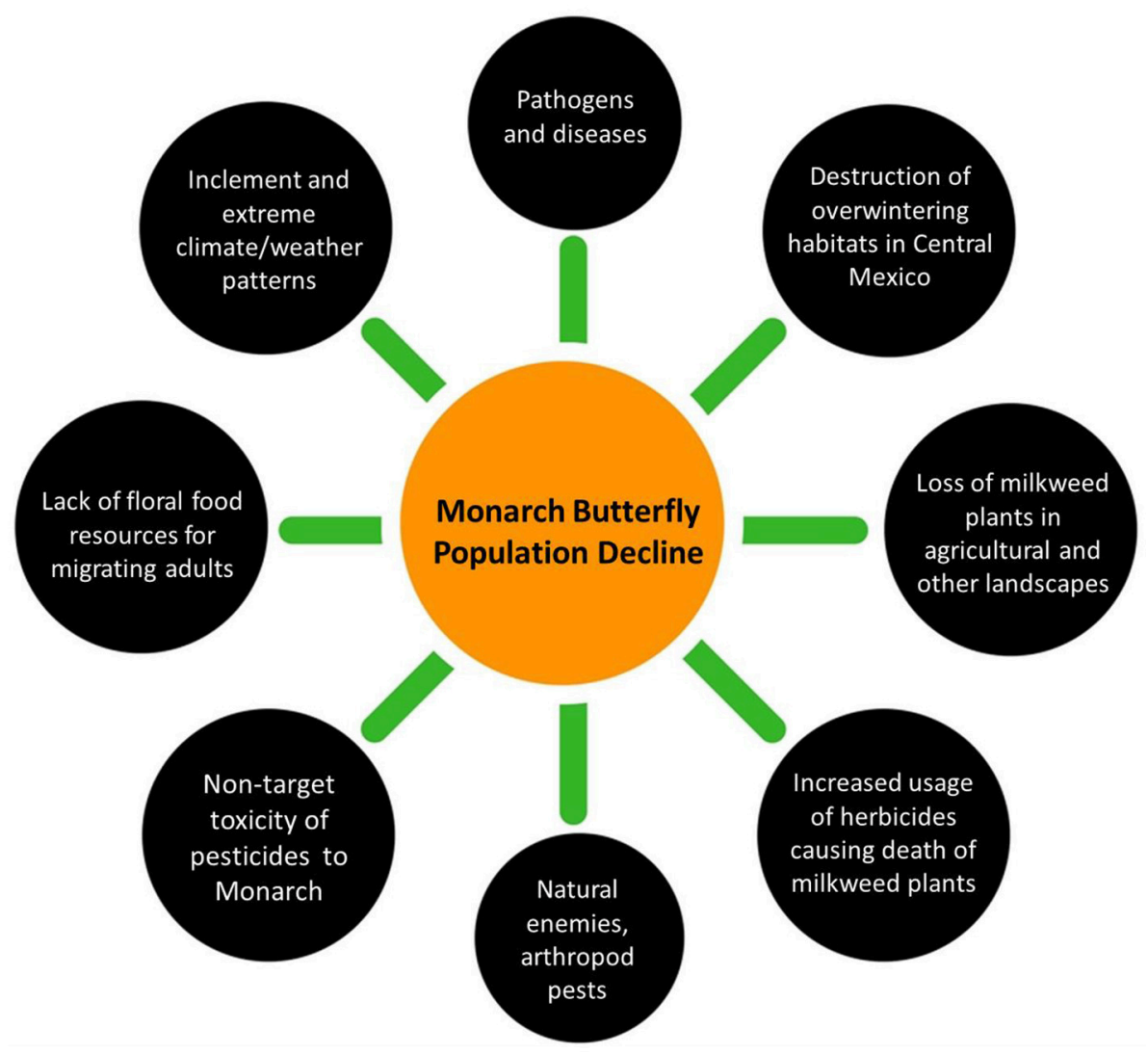

FIGURE 1 | Different factors affecting monarch butterfly population in North America. 
to $1 \mathrm{ppb}$ of clothianidin (Pecenka and Lundgren, 2015). Clothianidin is the main neonicotinoid insecticide used on maize fields (Hopwood et al., 2016), where milkweed commonly grows, and has the potential for non-target effects on developing monarch larvae in maize fields throughout the United States.

Wide scale plantings of genetically modified (GM) crops such as maize, soybeans, and cotton have also been hypothesized to negatively impact developing monarch larvae. For instance, in a study, exposure of first instar larvae to low doses of Bacillus thuringiensis $(B t)$ maize pollen resulted in relatively lower body weight and lower survival rate (Stanley-Horn et al., 2001). However, the risks of $B t$ crops to monarchs have since been shown to be very low as a result of most maize pollen shed landing on milkweeds within maize fields on leaves within the center of the plant where monarch larvae are less likely to feed (Pleasants et al., 2001). Also, Scriber (2001) demonstrated no significant difference in the effects of larvae of several lepidopteran species fed leaves with and without dustings of $B t$-maize pollen, and Oberhauser et al. (2001) found that while monarchs in the midwestern United States use maize fields for their breeding habitats, they are as likely to be found in non-agricultural habitats.

In a 1999 survey of habitats containing common milkweed (Asclepias syriaca L.) Oberhauser et al. (2001) determined that the quantity of monarchs produced per ha in maize and soybeans fields was the same or higher as other habitats. After 1999, growers began rapidly adopting genetically modified glyphosate resistant (GR) varieties of maize and soybeans enabling them to increase their usage of glyphosate as an herbicide (Brower et al., 2012). The timing of this change is suggested to be closely linked with the beginning of monarch declines. The rapid surge of glyphosate usage in maize and soybean fields is hypothesized to have reduced $A$. syriaca abundance and hence the monarch summer breeding habitats once commonly found in these agroecosystems. Pleasants (2015) points out that glyphosate can affect monarchs directly by killing the milkweed plants that the larvae are feeding on, or indirectly by killing milkweed plants in general, which reduces the number of available plants for monarch to utilize as a host.

\section{INFLUENCE OF MODERN AGRICULTURAL PRACTICES AND CHANGING LANDSCAPES ON MONARCH BREEDING HABITATS AND MIGRATORY PATH}

Monoculture plantings of food and biofuel crops that have come to dominate the agricultural landscape of the midwestern United States have reduced the amount of floral resources available to adult monarch butterflies. For example, the Conservation Reserve Program (CRP) area was reduced by 2.02 million ha between 2006-2012 USDA (2012a) while over the same period, maize and soybeans planting increased by 6.88 and 0.49 million hectares, respectively (USDA, 2006, 2012b). This change in the agricultural landscape is exemplified by the conversion of large areas of grassland and rangeland that likely would have provided ample floral resources into biofuel crops (Stubbs, 2007). Intensive monoculture farming practices are also thought to have reduced the quantity of milkweed plants growing in fields. For example, Pleasants and Oberhauser (2013) determined that the quantity of milkweed decreased in Iowa agricultural and non-agricultural landscapes by 81 and $31 \%$ respectively between 1999 and 2010. This reduction culminates in an overall loss rate of $58 \%$ during this period. The loss in agricultural milkweed is attributed to the wide scale adoption of genetically modified crops and subsequent increase of glyphosate sprays (Pleasants and Oberhauser, 2013). Moreover, this study found a positive correlation between monarch reproduction in the midwest and the size of overwintering populations in Mexico. Using a densitydependent matrix projection model (Flockhart et al., 2015) concluded that reduction in milkweed in the United States is more significant in explaining monarch population declines than either the deforestation of overwintering sites or periodic weather. This finding corroborates the results of Pleasants and Oberhauser (2013). Since monarchs are larval host plant specialists, declines in landscape composition of milkweed directly influences essential components of their survival such as increasing both intraspecific larval competition and the searching time that ovipositing females must invest in looking for milkweed (Flockhart et al., 2012). In summary, while the decrease in milkweeds from agricultural fields has been the primary driver of eastern monarch declines, monarch butterfly populations continue to decline even though milkweed plants have been largely diminished from agricultural fields. For example, Pleasants (2017) determined that while milkweed declined by $40 \%$ between 1999 and 2014, the potential monarch host capacity declined by $71 \%$ over the same timeframe. Pleasants (2017) attributes this steep decline in monarch host habitat by calculating that agricultural milkweeds contain an average of 3.9 times more monarch eggs per stem, than those in nonagricultural settings. This further decline of monarchs is widely explained by an increased loss of milkweed stems resulting from land conversion from CRP and other native grassland habitats into large-scale commercial agricultural crop production.

Anthropomorphic changes in natural habitats may also influence bionomics of monarch by affecting availability of its host plants. For instance, in Arkansas, it has been suggested that the suppression of wildfires in natural habitats within the Ouachita Mountains has reduced the availability of nectar providing plants. This is especially true for Bidens aristosa plants that grow on road verges (Rudolph et al., 2006). Moreover, large quantities of monarch butterflies passing through the Ouachita Mountains each fall while migrating to central Mexico obtain nectar resources from flowering plants that primarily inhabit fire-disturbed areas. Fire suppression combined with prescribed burning which is used as a management tool in Arkansas forests Walkingstick and Liechty (2007) has been hypothesized to negatively impact monarch populations. It is thought that migrating monarchs encounter a shortage of food resources in burned areas within the Ouachita Mountains (Rudolph et al., 2006). We hypothesize that a lack of milkweed food resources reduces the realized fecundity of female monarchs given the extra time invested in finding suitable milkweed hosts. The adults 
that develop from the final generation of larvae are unlikely to be weakened unless the density of milkweed plants where they are feeding is low to the point that they cannot feed optimally. A dearth of nectar food resources as a result of decreased floral plants might weaken migrating monarch adults that are beginning their journey to central Mexico, however at that time, milkweeds are not important for these migratory adult monarch butterflies.

Quantifying the effects of climate and land use changes on monarch population dynamics between 1994 and 2013, Saunders et al. (2017) determined that spring seasons with higher precipitation and cooler temperatures in Texas were associated with higher summer population abundances in Illinois. They also found a negative association between glyphosate use and monarch summer population abundance during 1994-2003, however there was no significant relationship between these two variables for the second decade (2004-2013) (Saunders et al., 2017), suggesting a need of similar studies in other regions.

\section{NATURAL ENEMIES: ROLE OF PESTS, PATHOGENS, AND DISEASES}

The relationships between monarch butterflies and protozoan parasites have also been analyzed as a possible contributor to their recent declines. For example, Bartel et al. (2011) demonstrated that the monarch protozoan parasite Ophryocystis elektroscirrha prevalence increased during the host breeding season. However, it was also determined that monarchs sampled at two overwintering sites in Mexico had lower parasite prevalence than those sampled at summer breeding sites (Bartel et al., 2011). Similarly, Altizer et al. (2000) determined that non-migratory monarchs in southern Florida that continuously breed were over $70 \%$ parasite infested, while Western monarchs that migrate moderate distances to overwintering sites were $30 \%$ parasite infested and Eastern monarchs that migrate to Mexico were less than $8 \%$ parasite infested over a 30-year timespan. This thereby suggests that protozoan parasites primarily affect monarchs at their summer breeding locations. A concern with O. elektroscirrha parasites is that the increased planting of tropical milkweeds in the southwestern United States (which is intended to help monarchs) has enabled the establishment of a resident sedentary population that does not migrate to central Mexico, and which have high O. elektroscirrha infestation levels (Satterfield et al., 2015). While autumn migration to Mexico appears to decrease infestation levels from the general population Satterfield et al. (2015), return migration the following spring through the highly infected southwestern United States region is hypothesized to re-infect monarchs. Higher levels of cardenolides in milkweed species could lower O. elektroscirrha infestation. For instance, monarch larvae reared on A. tuberosa, feeding on higher doses of cardenolides resulted in lower parasite infestation of their pupae (Gowler et al., 2015).

Devising ecological niche models to identify areas with suitable abiotic conditions for six predators and two parasitoids of monarchs, McCoshum et al. (2016) concluded that the highest prevalence of these natural enemies is in areas along United States
Gulf Coast, parts of the West Coast, Florida, and throughout the eastern United States. Specifically, the models of McCoshum et al. (2016) predict that the Gulf Coast, parts of the West Coast, the Upper Midwest and southern Canada are most environmentally adept for the two parasitoids studied, Lespesia archippivora and Pteromalus cassotis. Among other natural enemies, the monarch generalist predator Arilus cristatus was found to have the most habitat suitability from the Great Lakes to Florida and Mexico, while predatory wasps (Polistes spp.) were found to have high environmental suitability throughout Mexico and the United States, and low suitability in Canada (McCoshum et al., 2016).

\section{CLIMATE: IMPACT OF SEASONAL PHENOLOGY CHANGES}

Understanding the impacts of climate change on monarchs is complicated because they migrate through multiple microclimates that may fluctuate throughout their journey. To explain monarch summer breeding phenology and year-toyear fluctuations in population abundances, Zipkin et al. (2012) built a Poisson regression model to estimate summer arrival times and resulting abundances in the United States Midwest. A finding from this study is that high levels of precipitation and intermediate spring temperatures in Texas were correlated with the largest population abundance and arrival to summer breeding habitats in Ohio (Zipkin et al., 2012). However, the weather patterns within Ohio do not affect the arrival of monarchs to this location, and once in their summer breeding habitat, monarchs are minimally affected by precipitation (Zipkin et al., 2012). This suggests that monarchs are only affected by climatic conditions in certain points along their migratory path and only at specific times of the year. Similarly, Saunders et al. (2017) determined that spring seasons with $\geq 13.34$ centimeters of precipitation and cooler temperatures (280-310 growing degree days) in Texas were associated with higher summer population abundances of monarchs in Illinois during the period 1994-2003. During the subsequent period of 2004-2013, Saunders et al. (2017) found that expected counts of summer monarch populations in Illinois were higher following spring seasons with 12.7-17.78 centimeters of precipitation in Texas and with almost equal (280-305 growing degree days) cooler temperatures. Brower et al. (2012) mention that severe cold during overwintering and temperature fluctuations during the spring and summer all threaten monarch survivorship, fecundity and alter larval growth rates. For example, during the summer of 2009, low temperatures in the Corn Belt minimized growth of summer generations and severely reduced monarch abundance in the 2009 fall migration (Taylor, 2009). Meanwhile, high temperatures in the spring of 2009 affected monarchs migrating north from overwintering (Brower et al., 2012).

Batalden et al. (2007) used ecological niche modeling to analyze the specific ecological habitats that monarch butterflies utilize during each of the summer months. Their findings suggest that monarchs engage in niche-following for each of their summer breeding generations exemplified by warmer and wetter 
climates and niche-switching during the overwintering phase of their annual lifecycle, marked by reproductive diapause in central Mexico and continuation of breeding niches along the Atlantic Coast of Central America (Batalden et al., 2007). Applying this data to future climate scenarios, Batalden et al. (2007) predict that monarchs may see an increase in ecologically suitable niches during the spring, assuming that they are capable of faster migration over larger distances. However, by the summer, ideal ecological-niches shift northward over a projection of the next 50 years, marking a clear separation from the current monarch summer range (Batalden et al., 2007). Therefore, monarchs and milkweed plants must follow these climatic shifts in order for monarchs to maintain distributional area during their summer breeding period (Batalden et al., 2007).

\section{MONARCH CONSERVATION EFFORTS}

As a result of the recent declines of monarch butterflies, several efforts to conserve their populations have been made. In North America, organizations such as Save Our Monarchs and the Monarch Butterfly Conservation Fund (MBCF) distribute free milkweed seeds and invest in projects to increase the availability of high quality monarch habitat (saveourmonarchs.org; www. nfwf.org/monarch). More specifically, research grants to increase breeding habitats and spread awareness of monarch conservation are awarded by the MBCF and supported by the Monsanto Company and other USDA-affiliated groups that focus on wildlife conservation.

In central Mexico, efforts have been made to discourage logging operations of the Oyamel Fir trees, Abies religiosa that monarchs congregate on during their overwintering period. For example, working with local communities, the WWF-Tecel Alliance successfully reforested 9,822.93 hectares of monarch butterfly sanctuaries with 10.73 million Oyamel Fir trees between 2003 and 2015 (www.wwf.org.mx) ${ }^{1}$. The WWF has also promoted sustainable tourism in this region through investments to improve infrastructure, equipment and training. Moreover, enforcement by Mexican authorities to curtail illegal logging and financial support from environmental philanthropists and businesses to help create alternative sources of income have reduced the quantity of deforestation (Vidal et al., 2013). Deforestation quantity overtime has been scientifically mapped through the use of aerial photography, satellite images, and field surveys (Vidal et al., 2013). Saenz-Romero et al. (2012) devised simulation models to predict the quantity of suitable habitat for the $A$. religiosa trees utilized by overwintering monarchs in central Mexico and best practices for future A. religiosa habitat conservation efforts. Using a bio-climate model incorporating summer and winter mean temperatures and annual vs. summer precipitation, Saenz-Romero et al. (2012) generated models forecasting a rapid decline of $A$. religiosa habitat, and specifically projected a $69.2 \%$ reduction in habitat by 2030 , an $87.6 \%$ reduction in habitat by 2060 , and a $96.5 \%$ reduction in habitat by 2090 .

${ }^{1}$ World Wildlife Fund (WWF). 96\% of all Deforestation within Mexico's Monarch Butterfly Sanctuaries Occur in a Single Community. www.wwf.org.mx.
The findings of current research projects on the effects of monarch conservation initiatives justify the need for future conservation efforts. For example, Saenz-Romero et al. (2012) suggest initiating conservation efforts by planting $A$. religiosa trees at higher elevations at transects of $300 \mathrm{~m}$, however variables including tree genetic adaptability and seedling tolerance to frosts and colder weather are currently unknown (Saenz-Romero et al., 2012). Additionally, Saenz-Romero et al. (2012) suggest that future work might investigate the potential of replacing $A$. religiosa with new plantings of a different species of tree that is more tolerant to climatic changes. Most importantly, it is also unknown whether or not migrating populations of monarchs will naturally adapt to overwintering on either trees planted at higher altitudes or trees of a different species (Saenz-Romero et al., 2012). Therefore, future research efforts investigating the interactions of these variables are warranted. In another recent study, creating a Bayesian multivariate auto-regressive statespaced model, Semmens et al. (2016) predicted an extinction rate of between 11 and $57 \%$ over a 20 -year period. The predictions of this model exemplify the potentially high risks of monarch quasi-extinctions and serious threats to their future survival.

\section{KNOWLEDGE GAPS AND RECOMMENDATIONS FOR FUTURE RESEARCH}

Several factors in the unique lifecycle and annual migration of the monarch butterfly warrant further exploration. While the effects of different $B t$ strains on monarch larvae (in field realistic scenarios) has been put to rest, we lack sufficient knowledge of the acute and sub-lethal toxicity of different pesticides commonly used in agricultural field crops to monarchs. For example, we discussed a study on the effects of clothianidin on monarchs foraging milkweed in maize fields; similar studies exploring the effects of other major neonicotinoids and other modern pesticides that are commonly used in row crop agriculture on monarchs is warranted. Additionally, work investigating potential synergisms of insecticide and fungicide mixtures as well as premix herbicide formulations to monarchs should be explored. These studies should ideally be conducted in both laboratory and field settings.

There is also a dearth of knowledge on the effects of landuse changes and habitat manipulation in different points of the migratory pathway that monarchs follow each year. For example, the study by Rudolph et al. (2006) mentions that preventing forest fires in Arkansas could result in a shortage of floral food resources for fall monarchs migrating to Mexico. Along these lines, we also need more information on the effects of monoculture farming practices, increased usage of GMO crops and herbicide applications on monarch breeding habitats. As part of this analysis, correlations between changes in milkweed abundance, floral resources and monarch population levels should be further investigated over time for statistical significance. Along these lines, we lack substantial data on the effects of conservation efforts such as the CRP plantings and other farm, city and community plantings of milkweed and other flowering plants on 
monarch abundance. Further exploration of overwintering sites in Mexico and the effects of habitat destruction in these areas are needed. A more in-depth analysis of the effects of natural enemies, such as protozoan parasites on monarch populations at different times throughout the year and along different points throughout their migratory path needs to be researched. Finally, we need more detail on the effects of climate change and weather oscillations on monarch survivorship and fecundity at different points encompassing the entire migratory range throughout the butterfly's entire annual life cycle.

Future studies researching the impacts of modern pest management on monarch declines should investigate the biological impacts on monarchs from exposure to pollens from genetically modified crops, pesticides (including formulated pesticide mixtures) sprayed on these crops, and their possible synergistic toxicity. Ideally, both laboratory and field studies should be conducted to determine if these chemicals have significant acute and sub-lethal toxicity to monarchs. Within time, it would be useful to determine if chemical exposure can change monarch behavior, in a similar fashion to the way, Ciarlo et al. (2012) demonstrated that agricultural chemical exposure changes honey bee behavior by impairing their ability to remember the previously learned task of feeding. Learning and memory skills might be important components in the ability of monarchs to accurately make their annual autumn migration to central Mexico and return migration to the United States and southern Canada during the following spring. As part of current research efforts regarding the effects of modern agricultural pesticides on monarchs, it would be interesting to examine the behavioral impact on monarchs when exposed to different pesticides. Research on the impact of modern agricultural practices on monarch breeding and migration should investigate the effects of increased stress on monarchs resulting from diminished milkweed resources in breeding habitats and floral food resources along the overwintering migration path. In relation to monarch natural enemies, it would be interesting to investigate if there is a correlation between reduced milkweed habit, sub-lethal pesticide exposure and protozoan parasite abundance in monarchs. If sub-lethal pesticide exposure and increased stress resulting from diminished food resources weakens monarchs, it is possible that they subsequently become more vulnerable hosts to protozoan parasites. While studies on the effects of climate change on monarch survival show the difficulty in determining how monarchs will be affected

\section{REFERENCES}

Altizer, S. M., Oberhauser, K. S., and Brower, L. P. (2000). Associations between host migration and the prevalence of a protozoan parasite in natural populations of adult monarch butterflies. Ecol. Entomol. 25, 125-139. doi: 10.1046/j.1365-2311.2000.00246.x

Bartel, R. A., Oberhauser, K. S., de Roode, J. C., and Altizer, S. M. (2011). Monarch butterfly migration and parasite transmission in eastern North America. Ecology 92, 342-351. doi: 10.1890/10-0489.1

Batalden, R. V., Oberhauser, K., and Peterson, A. T. (2007). Ecological niches in sequential generations of eastern north American monarch butterflies (Lepidoptera: Danaidae): the ecology of migration and likely climate by climatic conditions, they focus on anecdotal climatic events occurring in specific points along the monarch migratory path. An alternative approach would be to simulate climatic patterns throughout the entire monarch annual cycle along multiple points encompassing the entire range of their migratory path, not only during their breeding period in the eastern United States.

\section{CONCLUSIONS}

The population levels of monarch butterflies have declined in recent years and multiple hypotheses have been proposed to explain this phenomenon. Many scientists attribute the increased planting of genetically modified crops and herbicide spray applications in the midwestern United States to reductions of milkweed in agricultural crop fields. As a result, the food supply in monarch breeding habitats has subsequently been diminished. The toxicity of pesticides commonly used in agricultural settings to monarchs has also been somewhat explored. It is also agreed upon that to a lesser extent, habitat destruction as a result of logging in the overwintering sites in Mexico and inconsistent climatic conditions have contributed to the recent decline of monarch butterflies. This has given rise to several monarch conservation efforts in both North America and central Mexico. Protozoan parasites have been shown to affect monarchs in their breeding sites and the extent of their effects lingering into monarch overwintering sites is currently unknown. However, even with all of these results and hypotheses, there still are a substantial amount of questions regarding recent declines of monarch butterflies. Therefore, further research efforts to examine events throughout this butterfly's life cycle are needed.

\section{AUTHOR CONTRIBUTIONS}

NJ conceived the study framework. JB prepared the manuscript draft with inputs from NJ. All authors edited and approved the manuscript.

\section{ACKNOWLEDGMENTS}

Authors are thankful to the USDA-NIFA (Project \# ARK02527) and the UA System Division of Agriculture for support. Authors are also thankful to reviewers for their feedback on a previous draft of this review article. The views and opinions expressed in this article are solely those of the authors.

change implications. Environ. Entomol. 36, 1365-1373. doi: 10.1603/0046225X(2007)36[1365:ENISGO]2.0.CO;2

Brower, L. (1996). Monarch butterfly orientation: missing pieces of a magnificent puzzle. J. Exp. Biol. 199, 93-103.

Brower, L. P., Taylor, O. R., Williams, E. H., Slayback, D. A., Zubieta, R. R., and Ramirez, M. I. (2012). Decline of monarch butterflies overwintering in Mexico: is the migratory phenomenon at risk?. Insect Conserv. Div. 5, 95-100. doi: 10.1111/j.1752-4598.2011. 00142.x

Ciarlo, T. J., Mullin, C. A., Frazier, J. L., and Schmehl, D. R. (2012). Learning impairment in honey bees caused by agricultural spray adjuvants. PLoS ONE 7:e40848. doi: 10.1371/journal.pone.0040848 
Elbert, A., Haas, M., Springer, B., Thielert, W., and Nauen, R. (2008). Applied aspects of neonicotinoid uses in crop protection. Pest. Manage. Sci. 64, 1099-1105. doi: 10.1002/ps.1616

Flockhart, D. T., Martin, T. G., and Norris, D. R. (2012). Experimental examination of intraspecific density-dependent competition during the breeding period in monarch butterflies (Danaus plexippus). PLoS ONE 7:e45080. doi: 10.1371/journal.pone.0045080

Flockhart, D. T., Pichancourt, J. B., Norris, D. R., and Martin, T. G. (2015). Unravelling the annual cycle in a migratory animal: breeding-season habitat loss drives population declines of monarch butterflies. J. Anim. Ecol. 84, 155-165. doi: 10.1111/1365-2656.12253

Gowler, C. D., Leon, K. E., Hunter, M. D., and de Roode, J. C. (2015). Secondary defense chemicals in milkweed reduce parasite infection in monarch butterflies, Danaus plexippus. J. Chem. Ecol. 41, 520-523. doi: 10.1007/s10886-0150586-6

Hopwood, J., Code, A., Vaughan, M., Biddinger, D., Shepherd, M., Hoffman Black, S., et al. (2016). How Neonicotinoids Can Kill Bees: The Science Behind the Role These Insecticides Play in Harming Bees, 2nd Edn, eds J. Hopwood, A. Code, M. Vaughan, D. Biddinger, M. Shepherd, S. Hoffman-Black, E. Lee-Mader and C. Mazzacano (Xerces Society for Invertebrate Conservation), 1-76. Available online at: http://whc.unesco.org/en/list/1290.

McCoshum, S. M., Andreoli, S. L., and Stenoien, C. M. (2016). Species distribution models for natural enemies of monarch butterfly (Danaus plexippus) larvae and pupae: distribution patterns and implications for conservation. J. Insect Conserv. 20, 223-237. doi: 10.1007/s10841-016-9856-Z

Oberhauser, K. S., Prysby, M. D., Mattila, H. R., Stanley-Horn, D. E., Sears, M. K., Dively, G., et al. (2001). Temporal and spatial overlap between monarch larvae and corn pollen. Proc. Natl. Acad. Sci. U.S.A. 98, 11913-11918. doi: $10.1073 /$ pnas. 211234298

Pecenka, J. R., and Lundgren, J. G. (2015). Non-target effects of clothianidin on monarch butterflies. Sci. Nat. 102, 1270. doi: 10.1007/s00114-015-1270-y

Pleasants, J. M. (2015). "Monarch butterflies and agriculture," in Monarchs in a Changing World: Biology and Conservation of an Iconic Insect, eds K Oberhauser, S. Altizer and K. Nail (Ithaca, NY: Cornell University Press), 169-178.

Pleasants, J. M. (2017). Milkweed restoration in the Midwest for monarch butterfly recovery: estimates of milkweeds lost, milkweeds remaining and milkweeds that must be added to increase the monarch population. Insect Conserv. Div. 10, 42-53. doi: 10.1111/icad.12198

Pleasants, J. M., Hellmich, R. L., Dively, G. P., Sears, M. K., Stanley-Horn, D. E., Mattila, H. R., et al. (2001). Corn pollen deposition on milkweeds in and near cornfields. Proc. Natl. Acad. Sci. U.S.A. 98, 11919-11924. doi: $10.1073 /$ pnas. 211287498

Pleasants, J. M., and Oberhauser, K. S. (2013). Milkweed loss in agricultural fields because of herbicide use: effect on the monarch butterfly population. Insect Conserv. Div. 6, 135-144. doi: 10.1111/j.1752-4598.2012. 00196.x

Rudolph, D. C., Ely, C. A., Schaefer, R. R., Williamson, J. H., and Thill, R. E. (2006). Monarch (Danaus plexippus L. Nymphalidae) migration, nectar resources and fire regimes in the Ouachita Mountains of Arkansas. J. Lepidopterists Soc. 60, $165-170$.

Saenz-Romero, C., Rehfeldt, G. E., Duval, P., and Lindig-Cisneros, R. R. (2012). Abies religiosa habitat prediction in climatic change scenarios and implications for monarch butterfly conservation in Mexico. For. Ecol. Manage. 275, 98-106. doi: 10.1016/j.foreco.2012.03.004
Satterfield, D. A., Maerz, J. C., and Altizer, S. (2015). Loss of migratory behavior increases infection risk for a butterfly host. Proc. R. Soc. Lond. B Biol. Sci. 282, 1-9. doi: 10.1098/rspb.2014.1734

Saunders, S. P., Ries, L., Oberhauser, K. S., Thogmartin, W. E., and Zipkin, E. F. (2017). Local and cross-seasonal associations of climate and land use with abundance of monarch butterflies Danaus plexippus. Ecography 41, 278-290. doi: $10.1111 /$ ecog.02719

Scriber, J. M. (2001). Bt or not Bt: is that the question? Proc. Natl. Acad. Sci. U.S.A. 98, 12328-12330. doi: 10.1073/pnas.241503398

Semmens, B. X., Semmens, D. J., Thogmartin, W. E., Wiederholt, R., L?pezHoffman, L., Diffendorfer, J. E., et al. (2016). Quasi-extinction risk and population targets for the Eastern, migratory population of monarch butterflies (Danaus plexippus). Sci. Rep. 6:23265. doi: 10.1038/srep23265

Stanley-Horn, D. E., Dively, G. P., Hellmich, R. L., Mattila, H. R., Sears, M. K., Rose, R., et al. (2001). Assessing the impact of CrylAb-expressing corn pollen on monarch butterfly larvae in field studies. Proc. Natl. Acad. Sci. U.S.A. 98, 11931-11936. doi: 10.1073/pnas.211277798

Stubbs, M. (2007). Land Conversion in the Northern Plains. Congressional Research Service Report for Congress RL33950.

Taylor, C. (2009). Monarch Population Status. Monarch Watch Blog. Available online at: http://monarchwatch.org/blog/2009/10/monarch-populationstatus-5/ (Accessed December 10, 2017).

USDA (2006). Acerage. National Agricultural Statistics Service (NASS). Available online at: http://usda.mannlib.cornell.edu/usda/nass/Acre//2000s/2006/Acre06-30-2006.pdf

USDA (2012a). Fiscal Year 2012 Annual Summary and Enrollment Statistics. Conservation Reserve Program, Farm Service Agency. Available online at: https://www.fsa.usda.gov/Assets/USDA-FSAPublic/usdafiles/Conservation/ PDF/summary12.pdf

USDA (2012b). Acerage. National Agricultural Statistics Service (NASS). Available online at: http://usda.mannlib.cornell.edu/usda/nass/Acre//2010s/2012/Acre06-29-2012.pdf

Vidal, O., López-García, J., and Rendón-Salinas, E. (2013). Trends in deforestation and forest degradation after a decade of monitoring in the Monarch Butterfly Biosphere Reserve in Mexico. Conserv. Biol. 28, 177-186. doi: $10.1111 /$ cobi.12138

Vidal, O., and Rendón-Salinas, E. (2014). Dynamics and trends of overwintering colonies of the monarch butterfly in Mexico. Biol. Conserv. 180, 165-175. doi: 10.1016/j.biocon.2014.09.041

Walkingstick, T., and Liechty, H. (2007). Why We Burn: Prescribed Burning as a Management Tool. University of Arkansas Extension FSA5009.

Zipkin, E. F., Ries, L., Reeves, R., Regetz, J., and Oberhauser, K. S. (2012). Tracking climate impacts on the migratory monarch butterfly. Global Change Biol. 18, 3039-3049. doi: 10.1111/j.1365-2486.2012.02751.x

Conflict of Interest Statement: The authors declare that the research was conducted in the absence of any commercial or financial relationships that could be construed as a potential conflict of interest.

Copyright (c) 2018 Belsky and Joshi. This is an open-access article distributed under the terms of the Creative Commons Attribution License (CC BY). The use, distribution or reproduction in other forums is permitted, provided the original author(s) and the copyright owner(s) are credited and that the original publication in this journal is cited, in accordance with accepted academic practice. No use, distribution or reproduction is permitted which does not comply with these terms. 